\title{
The Intentions of International Tourists to Attend the 2016 Rio Summer Olympic and Paralympic Games: A Study of the Image of Rio de Janeiro and Brazil
}

\author{
Leonardo Jose Mataruna-Dos-Santos* \\ College of Business Administration, American University in the Emirates, Dubai, UAE. \\ Submitted 22 September 2019; Accepted in final form 27 February 2020.
}

\begin{abstract}
Background. This paper investigates how hosting a mega sports event such as the 2016 Rio Games - Olympic and Paralympic influence the Rio de Janeiro and Brazil image' like popular destinations among tourists. Objectives. The following hypotheses guided our research to identify the more positive image of Brazil as a tourism destination. Methods. A mixed research design combining both qualitative and quantitative approaches was used. Participants were recruited at the Technische Universität München and in the city center of Munich, Germany. The two dimensions (cognitive and affective) of the tourism destination image were considered to elaborate a questionnaire survey, which mixes both qualitative and quantitative methods. Results. The significant factors influencing the intentions of a person to attend the Games in Brazil are the positive portrayed image of the country and their sport interest. According to the multiple regression conducted, the only variables, which have influenced people's intention to go to Brazil for the Olympics, were the image of the country as a tourism destination $(\beta=0.404, p<0.05)$ and sports interests $(\beta=0.259$, $\mathrm{p}<0.05)$. The same influence of these variables was observed when the independent variable is the intention to go for the Paralympics: an image of Brazil as a tourism destination $(\beta=0.377, \mathrm{p}<0.05)$ and sports interest $(\beta=0.205, \mathrm{p}<$ 0.05 ) have influenced respondent's intention. Conclusions. Furthermore, the study revealed the hosting of the Olympic Games had a more considerable influence on a person's intentions to visit the country than the hosting of Paralympic Games. It was also observed that the media played a significant aspect in the construction of an opinion on a tourism route. Also, a semantic analysis presented a different image' of the country, even when the intention to attend the Olympics was low.
\end{abstract}

\section{KEYWORDS: Brazil, Olympic Games, Paralympic Games, Foreigners, Tourism Destination Image}

\section{INTRODUCTION}

Since the Confederations FIFA Cup held in Brazil in 2013, it has drawn attention because of the sports mega-events it has been hosting; the 2014 FIFA World Cup and the next Olympic and Paralympic Games, on August and September 2016. After hosting the Pan-American and Para Pan Games in 2007, Brazil promoted the identity of the country of tourism destination for receiving other mega-events, such as FIFA world cup (1).
A sport mega-event attracts audiences from around the globe (2), which can help the host nation to portray strong cultural and social values in addition to displaying its economic and political might (3-5).In recent years, the relevance of the relationship between the tourism sector and the Olympic Games has gained increased recognition (6). The intensive media coverage engulfing the Olympic Games presents an

*. Corresponding Author:

Leonardo Jose Mataruna-Dos-Santos, Assistant Professor

E-mail: mataruna@gmail.com 
opportunity for a city to advertise itself to potential tourists; one of the critical factors in a nation's bid to host a sports mega-event.

The goal of this study is to examine the effect of sports mega-events on Brazil from a tourism perspective, by analyzing International Tourists' intention to attend the 2016 Olympic and Paralympic Games. The factors influencing the perceived image of Brazil among the international tourists, who have never visited Brazil, will also be examined. These are some of the elements addressed through a questionnaire survey with both quantitative and qualitative methods. The survey was applied in Munich, Germany. The study is part of the Carnival project, an initiative for studying the impact of the mega-events, funded by the European Union, and is being conducted at the Technische Universität München (TUM).

In April 2016, a preliminary pilot study was conducted by the authors of this paper with a similar questionnaire which aimed to extract the image of Brazil as a tourism destination and the influence it could have on a foreigner planning to pay a visit to the country during the Summer Olympic and Paralympic Games. Thirty-five $(\mathrm{n}=$ 35) people participated in this study, which revealed an overall positive image of the country. However, although they presented a positive image of the country, it did not directly translate into an increased likelihood of visiting the country and attending the Games. Then, the preliminary study gave support for new variables included in this paper, such as interest in sports, safety and health perceptions, and pricing and crowding perceptions that might influence foreigners' intention to travel to Brazil during the Olympics.

Previous research on the same topic (7-9) has also been done primarily during the 2014 FIFA world cup in Brazil, where foreign visitors inside Brazil were researched. The relevance of our study comes from the fact that it was performed outside Brazil, targeting International visitors who have never been to Brazil, thus resulting in a new and different perspective.

Theoretical Framework. According to Getz (10), the impact of a mega-event on tourism can be analyzed through a special focus on destination profiling and marketing. The post-event benefits can be leveraged by utilizing this technique which takes into consideration the tourist arrivals not only during that period but also other times of the year. Thus, to verify the image that foreigners have created about Brazil, either by experience or external factors such as word of mouth, TV, Internet, etc., and their likelihood to visit Brazil during the context of the 2016 Olympic Games, we are going to apply a theoretical framework on sports mega-events and tourism, destination image, and tourism management.

Sports Mega-Events and Tourism. According to Zagnoli and Radicchi (11), sport mega-events can have a significant positive impact, such as pinpointing a destination in the world's tourism radar, nurturing economic, social, and urban development, and even altering the uneven/unfair contribution of a country in the international economy (11). One of the main aspects of the mega-events is the media attention they have from the very beginning when the rights of hosting are awarded to a city or a nation. Horne(2) states that sports mega-events have a strategic role in contemporary society, influenced by capitalism. Through these events, countries are looking forward to promoting their image in the international arena. Thus this is why mega-events play an essential role nowadays for economies in different tourist destinations. Roche (12) points out the cultural perspective of the mega-events, mainly because of the worldwide impact they have. Spencer-Oatey (13), define cultural perspective as a "viewing a situation or concept through the eyes of an individual's native environmental and social influence. It is the influence that culture and society have on a person's worldview and perspective."

A positive image of the host city in the media is a key to attract new visitors not only during the event but also after the event such as those who couldn't visit during the event. Media coverage of the event organizers and the associated infrastructure plays a pivotal role in determining the attractiveness of a former host after an event (14). The impression formed in the minds of the viewers through the attractive media coverage of the culture and lifestyle might influence the desire of a viewer to visit the country. Unfortunately, the image of a country as a tourist destination can be hampered by the negative media coverage related to crimes against tourists (15). On the other hand, the steep increase in expenses associated with the hosting of a mega-event combined with the influx of tourists for the mega-event can prove to be a bane for a host city by deterring the regular tourists from visiting the country. The business 
travelers and even residents might be diverted to nearby tourist hotspots to combat and escape the congestion generated due to the high volume of traffic of new visitors (16).

Destination Image. Tourism destination image is "an amalgam of knowledge, feelings, beliefs, opinions, ideas, expectations, and impressions people have about a named location" (17): Bingné, Sánchez, and Sánches (18) present destination image as the subjective interpretation of reality by the tourist. Therefore, San Martin and Rodriguez (19) emphasize that a soft personal vision of a destination based on the perception of each tourist exists through their previous travel experiences to different tourist destinations.

A consumer's rationality and emotionality foster the development of an image of a tourist destination (20). The cognitive senses help a tourist in evaluating and giving due importance to the various attributes attached to the resources and attractions of a tourist destination (21). The affective reasons strongly influence the emotional attachment generated towards a tourist address (22).

Therefore, the combination of cognitive and affective components along with the actual experience as a tourist in the city plays an instrumental role in the formation of a destination image (22-24).

The various outlets of information such as media, tourist agencies, and online travel forums (TripAdvisor) aid the cognitive process of destination image formation. According to various literature sources, the amount and quality of available information define the nature of a constructed image (25). The possibility of an individual forming an image of a destination without paying a visit to the location, age of an individual, the race of an individual and previous experiences through a visit to tourist destinations are a few factors which play a pivotal role in the image formation and perception of a tourist destination (26).

Tourist satisfaction and destination image have a positive relationship with research suggesting the destination image to be a major influential factor in the achievement of tourist satisfaction (27-29).

Hypotheses. Considering the theoretical framework presented, this paper presents research hypotheses are as follows: H1 Positive image of Brazil as a tourist destination is positively influencing the intention to attend the Olympic
Games. H2 Higher degree of sports interest is positively influencing the intention to attend the Olympic Games. H3 Positive perception about safety and security is positively influencing the intention to attend the Olympic Games. H4 Perception of being crowded is negatively influencing the intention to attend the Olympic Games. H5 Perception of being an expensive affair is negatively influencing the intention to attend the Olympic Games.

The following model variables are included (Figure 1):

1. Dependent variables - Intention to attend the Olympic Games.

2. Independent variables:

2.1. Positive Image of Brazil as a Tourist Destination (Image).

2.2. Interest in Sport (Interest).

2.3. Perception of Safety and Security (Safety).

2.4. Perception of Overcrowding (Crowd).

2.5. Perception of Price (Cost).

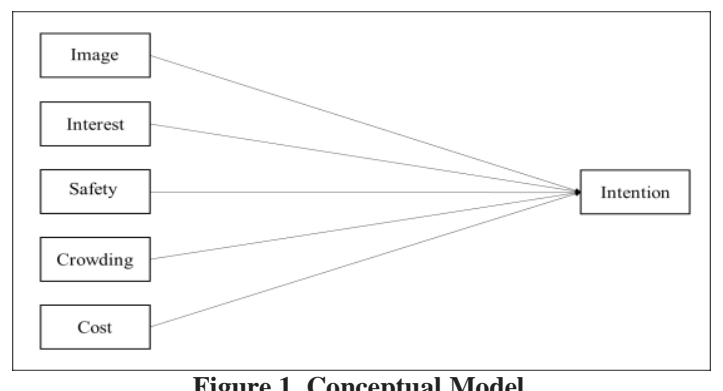

Figure 1. Conceptual Model.

Sport Mega-Events in Brazil and Tourism. Tourism is a segment in the national development plan created by the government in Brazil, such as the FIFA World Cup and the Olympics, which would be an opportunity to attract international and national visitors to the country. The amount of public budget invested into this sector looking forward to the arrival of domestic and foreign tourists, enhance the promotion of the country image and generate a sustainable model to support the infrastructure, develop the principles of tourism and foster a healthy event organization.

Using other words, the government of Brazil had very high multi-sector expectations, including tourism, from hosting mega-events justifying its high level of investment, as revealed during political and media discourses during the years of preparation for the events. Thus what we will be looking at in the next topics in the tourism context during the Rio 2016 Games, in addition to recurrent tourist arrivals from the 2013 
Confederations Cup and FIFA 2014 World Cup events.

2013 Confederations FIFA Cup. During the hosting period of the Confederations Cup in 2013, the Brazilian Ministry of Tourism (30) researched the six cities where the matches happened. Overall, three thousand and sixty-nine $(3,069)$ tourists participated in the survey conducted in the stadiums and airports in Brasília, Belo Horizonte, Fortaleza, Recife, Rio de Janeiro, and Salvador. On average, the visitors were between 32 and 40 years old. And for at least $68.1 \%$ of them, the matches were the principal reason to visit Brazil at the time. The Brazilian government released that at least 25,000 tourists traveled to the country for this event (30).

FIFA World Cup 2014. The Brazilian Ministry of Tourism (31), after the 2014 FIFA World Cup, conducted a survey aiming to know about foreigners' experience in Brazil during the mega-event and their demographics. The study pointed out that $90.2 \%$ of the visitors traveled to Brazil, mainly because of the World Cup. Checking the most visited cities in ascending order, we can find we are and Salvador $(15,3 \%)$, Brasília (19,1\%), Belo Horizonte $(20,8 \%)$, São Paulo (43,3\%) and Rio de Janeiro (70,7\%). On average, each tourist visited two to three cities. According to the Ministry of Tourism (31), most of the tourists had a good experience visiting the country in the period of the FIFA World Cup 2014. This is not an exclusive fact of enjoying the events related to the World Cup, but the tourists had the opportunity to experience the Brazilian culture and lifestyle. On the overall, the infrastructure provided in the stadiums and other facilities of the World Cup were also well evaluated by the visitors. Furthermore, public and tourist services were well rated by foreigners.

Swart et al. 8, even went further in researching the potential of visitors' re-visitation to Rio de Janerio after the 2014 World Cup. According to their research, "destination image, reduced crimerisk perceptions, and satisfaction" positively influenced the possibility of visitors' re-visitation. The previous research supported the central finding of Swart et al.8; the probability of a tourist revisiting Rio de Janeiro increased after attaining satisfaction from an earlier trip to the city $(15,32-$ 34).

The model displayed that an increase in the various sources of information available to a tourist before a visit to Rio de Janeiro leads to a less positive image of the destination city. Earlier research by Fodness and Murray (35) had proposed a positive relationship between the outlets of information available to a tourist and a favorable destination image. The pre-event political unrest in the city of Rio de Janeiro and the following media coverage may have portrayed Brazil in a bad light among the backpacking tourists. The findings of their research verified the positive relationship existing between destination image and supposed crime-risk. Also, the previous study by Castro et al (28), Court and Lupton (29), and Fakeye and Crompton (36) aided the existence of a positive relationship between destination image and re-visitation of the city (8).

Expectations for the 2016 Olympic Games. Based on the experience the country had during the 2013 and 2014 football mega-events, similarly, the Brazilian government had big ambitions from hosting the Olympics in the country, especially in Rio de Janeiro. It will be the first Olympics held in the continent of South America, and the Ministry of Tourism estimates that during the event in Rio de Janeiro at least 380,000 foreign tourists will visit other cities and regions in Brazil. During the 2014 FIFA World Cup International tourists visited 491 different cities in Brazil31. Although the 2016 Olympic Games officially hosted in Rio, four other main cities hosted football matches of the Games. These were Belo Horizonte, Brasília, Salvador, and São Paulo. Because of this, the government believes more ports may be visited besides Rio de Janeiro.

The Brazilian Ministry of Tourism developed a couple of strategies to increase the number of visitors to the Olympics. Among those strategies were to: make the visa process easier for some nations, becoming not mandatory during the period of the Games; facilitate the sales of tourist packages; improve the skills and qualification of some professionals in strategic areas and tourists services; increase the wi-fi network infrastructure in the cities; stimulate new business in the tourism sector; the promotion of Rio and Brazil abroad; more investments in innovation and diversification of the tourism industry in the country (37).

\section{MATERIALS AND METHODS}

This research is looking for evidence on how the image of Brazil as a tourism destination influences foreigners' likelihood to visit Brazil 
during the 2016 Olympic Games. The two dimensions (cognitive and affective) of the tourism destination image were considered to elaborate a questionnaire survey, which mixes both qualitative and quantitative methods. The questionnaire was designed to reveal the image foreigners have of Brazil as a tourist destination, and also what is their intention to visit Brazil before, during or after the 2016 Olympic Games. Some variables were taken into account, such as the image itself they have of the country, sports interest, perceived health and safety conditions in Brazil, crowding, and pricing perception regarding the Games.

At first, an inclusion and exclusion criteria were used by starting with the question asking whether the International tourist has visited Brazil before. Secondly in an open-answer question, the respondents were asked to describe in three words what comes to their minds when they think of Brazil as a tourism destination; also, in a fivelevel rank Likert's scale (ranging from "Not at all" to "Very Much"), they were questioned on how elements like family and friends (word of mouth), media (internet, TV, newspapers, etc.), social media (Twitter, Facebook, Instagram, etc.), reference groups (such as celebrities or sport teams) and tourist agencies contributed in building an image of Brazil in their minds. Furthermore, they were asked how often they have been watching or reading news about Brazil since the 2014 World Cup, using on a five-level Likert scale (ranging from "never" to "always"). Then, based on Lepp's (38) involvement measurement, we created four items (StressfulRelaxing; Unpleasant-Pleasant; SleepyArousing; Boring-Exciting) to ask people how they see Brazil as a tourism destination, measured by a five-point scale. Based on the same theory, we asked them about their interest in sports by using three Lepp's items (UnimportantImportant; Irrelevant-Relevant; of no concern to me-of concern to me) and measuring it through a five-point scale. The next six questions asked foreigners to mark in a line, from 0 to 100 , how much they would like to visit Brazil during the 2016 Olympic and Paralympic Games, respectively.

Additionally, to understand the perception of International Tourists on issues like health, safety, and infrastructure conditions in Brazil, a question with nine positive and negative statements fashion was used, three statements for each item.
A Likert-type five-point scale was utilized (ranging from "Strongly disagree" to "Strongly agree"). The last question had the same structure as the previous one. However, it presented positive and negative statements regarding perceived crowding, pricing, and the experience of attending Rio de Janeiro during the 2016 Olympic Games. Finally, in the last section of the questionnaire, we asked for some demographic and personal information, such as age, gender, nationality, and place of permanent residence.

Data Collection. The questionnaire was applied during the spring of 2016 in two locations: city center of Munich and the university's campus to verify International Tourists' intention to visit Brazil during the next Olympic Games or Paralympic Games, before the event organized in Rio de Janeiro between on August and September of 2016.

Participants. The total participants was 90 respondents (Table 1), where all 90 respondents haven't visited Brazil before. This pilot study used convenience sampling, a non-probability sampling technique, where subjects are selected because of their convenient accessibility and proximity to the researcher. They were approached in touristic areas of the city center (central station, Karlsplatz, Marienplatz, and Marienhof), and also in the Technische Universität München, where a group of postgraduate students (all non-Germans) answered to the questionnaires.

\begin{tabular}{lcc}
\multicolumn{3}{c}{ Table 1. Respondents per Gender $(\mathbf{n}=\mathbf{9 0})$} \\
\hline Gender & Frequency & Percentage \\
\hline Female & 48 & 53.3 \\
Male & 42 & 46.7 \\
\hline
\end{tabular}

The analysis showed that of the 90 volunteer respondents $(\mathrm{n}=48)(53.3 \%)$ were female and $(\mathrm{n}=$ 42) $(46.7 \%)$ male, and comprised largely of young and middle-age individuals between 16-25 (64.4\%) and 26-35 (27.7\%), followed by $46-55$ $(5.5 \%)$ and $36-45(2.2 \%)$. A diverse array of countries was reported with Germany $(38.9 \%)$, Italy $(6.7 \%)$, the United States (4.4\%), Pakistan (4.4\%), India (4.4\%), Argentina (3.3\%) and South Korea $(3.3 \%)$ representing the largest groups. The majority of the respondents $(81.1 \%)$ cited Munich as their permanent residence, while $7.8 \%$ pointed out other cities in Germany, 3.3\% other cities in Europe, and $7.7 \%$ said their residence is in other continents (North America, South America, Africa, and Asia). 
Data Analysis. In this study, simple descriptive statistics, such as mean and percentage, and multiple regressions are applied to the analysis of the elements presented above. Moreover, a semantic analysis of the works cited by the respondents $(n=90)$ was used to understand qualitatively the image they have of Brazil. To apply the semantic analysis, we divided the respondents into two groups according to their intention (low and high) to visit Brazil during the 2016 Olympic Games.

\section{RESULTS}

Image of Brazil as a Tourism Destination. To verify the image qualitatively that foreigners have of Brazil as a tourism destination, we split the respondents into two groups the respondents according to their intention to visit the country during the Olympic Games. The median for the split for the purpose to travel at that time was 60 . Lower than 60 in group 1, which has a lower intention (Figure 2), and higher than 60 in group 2 (Figure 3), which has more top plans to travel to Brazil.

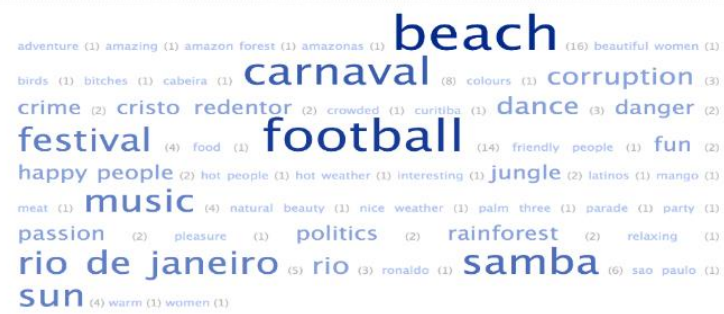

Figure 2. Low Intention Group, Semantic Graph

The semantic analysis of the low intention group reveals several words related to the Brazilian landscapes, nature, cities, and culture, such as amazon forest, rainforest, birds, palm trees, Amazonas, São Paulo, Curitiba, etc. The main words cited by the respondents in this group were beach (16), football (14), Carnaval (8), samba (6), and Rio de Janeiro (5) or Rio (3). They are all part of the ordinary imaginary people usually have when they think of Brazil. More words related to the carnival, party, and festival give us the idea people seen the country as a state of happiness and joy - festival (4), music (4), dance (3), happy people (2). Although many positive words have been cited, the respondents presented some negative ideas: corruption (3), crime (2), danger (2), politics (2), and bitches (1). A possible interpretation for these negative words is the media coverage, which has increased since the country started being prepared for the sports mega-events. Thus, besides news related to the mega-events, more stories about crimes, corruption, and the political situation in the country have been released. However, those aspects require more investigation opening a new research door for future study.

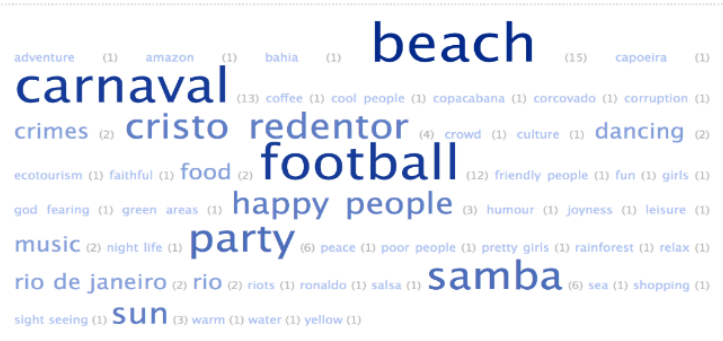

Figure 3. High Intention Group, Semantic Graph

By analyzing the high intention groups' words, it is possible to verify a more significant sample of positive words related to the Brazilian culture, lifestyle, landscapes, cities, and nature. The most cited words were beach (15), carnival (13), football (12), samba (6), a party (6), Christ the Redeemer Statue (4), sun (3), Rio de Janeiro (2) and Rio (2). Also, isolated words were also mentioned: capoeira, coffee, cool people, Corcovado, ecotourism, faithful, friendly people, humor, peace, sightseeing, water, yellow. They all are directly linked to the Brazilian people or lifestyle and tourism possibilities. Furthermore, some negative words were mentioned, such as corruption (1), crimes (2), poor people (1), riots (1), and slums (1).

By making a comparison of both groups, we can identify some similarities. To sum up their content, both groups mentioned the most known stereotypes of the country, such as football, beaches, and carnival - which are part of that collective imaginary about Brazil. They also mentioned cities like Rio de Janeiro and São Paulo, in addition to landmarks such as the symbolic statue of Christ the Redeemer on Corcovado Mountain in Rio de Janeiro. Another point in common is the mention of Brazilian nature, which is represented by the rainforest, the Amazonas River and also the beaches. Moreover, negative words were also common in both groups, which drives us to the idea that, apart from their intention, the image they have of Brazil is a mixed state of stereotypes, collective imaginary, and elements offered through the media coverage.

Image Destination Construction. To identify how the respondents created these ideas of Brazil 
as a tourism destination (Table 2), the study looked for evidence of what were the main influencing factors for the respondents to have established the image they have of Brazil as a tourism destination. The research scale was developed for this study to measure the model variables. The size was sent to three experts for the face and content validity. The experts and range suggested some minor improvements were improved accordingly. For the scale reliability, the Cronbach Alpha was measured, and it was 0.76 , which provided enough evidence of the scale reliability. According to the survey, the most influencing element affecting respondents' image of Brazil as a tourism destination was the media, followed by social media, then family and friends (word of mouth), reference groups (celebrities, sports teams, etc.) and tourist agencies.

Table 2. Image of Brazil as a Tourism Destination $(\mathbf{n}=\mathbf{9 0})$

\begin{tabular}{ccccccc}
\hline & Family and Friends & Media & Social Media & Reference Groups & Tourist Agencies \\
\hline Mean & 2.91 & 3.59 & 3.02 & 2.50 & 2.01 \\
\hline
\end{tabular}

The media influence in constructing destination's image was also questioned by the survey when International tourists in Munich were asked how often they have been reading or watching the news about Brazil since the 2014 FIFA World Cup (Table 3). The majority of the participants affirmed that news about Brazil has sometimes appeared in their daily media exposure since the country held the World Cup in 2014. Another significant amount of people said they have rarely received news about the country.

Table 3. Since the 2014 FIFA World Cup How Oten Have You Been Watching or Reading about Brazil $(n=90)$

\begin{tabular}{lcc}
\hline & Frequency & Percentage \\
\hline Never & 9 & 10.0 \\
Seldom & 29 & 32.2 \\
Sometimes & 33 & 36.7 \\
Often & 12 & 13.3 \\
Always & 7 & 7.8 \\
\hline
\end{tabular}

\section{Multiple Model Regression (Hypothesis 1 to} 5). With a multiple model regression, the relationship between the independent to the dependent variables was verified, thus exploring the five hypotheses presented previously (Table 5). Assumptions of independents of errors (Durbin Watson statistics) and normal distribution were checked in all analyses. ANOVA modality was present. For the first independent variable (Intention to go for the 2016 Olympic Games, $\mathrm{F}=6.136, \mathrm{p}<0.001)$ and the second (Intention to go for the 2016 Paralympic Games, $\mathrm{F}=5.016, \mathrm{p}<0.001$ ) model was significant. Additionally, for the Intention to go for the 2016 Olympic Games, 26.8\% of the variance was explained by the variables included in the model; and for the Intention to go for the 2016 Paralympic Games, 23\% of the variants were explained by the variable included in the model. The model was checked for collinearity statistics $(\mathrm{VIF}<1.8)$.

Table 4. Descriptive of Independent and Dependent Variables $(\mathbf{n}=90)$

\begin{tabular}{lc}
\hline Variables & Mean (SD) \\
\hline Image of Brazil as a tourism destination & $4.11(.691)$ \\
Sports interest & $3.70(1.87)$ \\
Safety and health perception & $3.00(.430)$ \\
Pricing perception & $3.44(.722)$ \\
Crowding perception & $3.38(.853)$ \\
Intention to go to the Olympic Games & $58.42(26.53)$ \\
Intention to go to the Paralympic Games & $52.08(27.01)$ \\
\hline
\end{tabular}

The analysis of the descriptive variables revealed the main aspects to be considered by this study (Table 4). The participants of the research presented a positive impression of the image of Brazil as a tourism destination $(\mathrm{M}=4.11)$. They also showed a particular interest in sports $(\mathrm{M}=$ $3.70)$, but not so clear perception of safety and health conditions in the country $(\mathrm{M}=3.00)$. The pricing and crowding because of the Olympic Games seemed to be perceived, or expected, by the respondents $(\mathrm{M}=3.44 ; \mathrm{M}=3.38)$. Their intention to travel to Brazil is higher during the Olympic Games $(58.4 \%)$ than in the Paralympic Games (52\%) period.

Table 5. Multiple Regression Model Results $(n=90)$

\begin{tabular}{lcc}
\hline Variables & $\begin{array}{c}\text { Intention to go for the 2016 Olympic Games } \\
\text { Std. Coefficients }(\boldsymbol{\beta})\end{array}$ & $\begin{array}{c}\text { Intention to go for the 2016 Paralympic Games } \\
\text { Std. Coefficients }(\boldsymbol{\beta})\end{array}$ \\
\hline $\begin{array}{l}\text { Image of Brazil as a tourism } \\
\text { destination }\end{array}$ & $.404^{*}$ & $.377^{*}$ \\
Sports interest & $-259^{*}$ & $.205^{*}$ \\
Safety and health perception & -.082 & -105 \\
Price perception & .153 & .167 \\
Crowding perception & -.102 & -.104 \\
\hline & "Dependent variable intention to go for the Olympic Games, $\mathbf{p}<\mathbf{0 . 0 5}$ \\
& "Dependent variable intention to go for the Paralympic Games, $\mathbf{p}<\mathbf{0 . 0 5}$
\end{tabular}


According to the multiple regression conducted, the only variables, which have influenced people's intention to go to Brazil for the Olympics, were the image of the country as a tourism destination $(\beta=0.404, p<0.05)$ and sports interests $(\beta=0.259, \mathrm{p}<0.05)$. The same influence of these variables was observed when the independent variable is an intention to go for the Paralympics: the image of Brazil as a tourism destination $(\beta=0.377, p<0.05)$ and sports interest $(\beta=0.205, p<0.05)$ have influenced respondent's intention. In either case, the other independent variables influenced the intentions of a potential attendee of the Olympic or Paralympic games to visit the country. Furthermore, even though the result is not significant, for both dependent variables, and safety and health conditions $(\beta=$ $0.082 ; \beta=-0.105)$ hurt the intention to travel to the country. Another variable that is not representative in terms of results, but had a negative effect in both dependent variables, is the crowding perception $(\beta=-0.102 ; \beta=-0.104)$. The price perception $(\beta=0.153 ; \beta=0.167)$ did not have a negative effect. In addition to this, it does not directly influence the intention to travel to Brazil during the Olympics or the Paralympics.

\section{DISCUSSION}

This research revealed that the intention to travel to Brazil during the Olympic or Paralympic Games is directly influenced by the image people have of Brazil (H1) and their sports interest (H2). The other variables $(\mathrm{H} 3, \mathrm{H} 4, \mathrm{H} 5)$ verified by this study do not seem to influence foreigners' intention to travel to the country during that period. Moreover, regarding the plan to go to Brazil, the analysis showed a higher purpose to pay a visit to Rio de Janeiro during the Summer Olympic Games (58.4\%) than during the Paralympics (52\%).

To begin with, by doing the semantic analysis of the works cited by the respondents $(\mathrm{n}=90)$ divided into two main groups according to their low or high intentions to visit Brazil during the 2016 Olympic Games or Paralympic Games, it was possible to verify many common words, some of them are stereotypes of Brazil. These words were related to the Brazilian cities (Rio de Janeiro, especially), culture (music and festivals), nature, cuisine, and sport. Thus we could notice that the general image of the country is a combination of affective and cognitive components, as argued by Mazursky and Jacoby24 and Stern and Krakover (23).

In both groups, the analysis pointed out a positive image of the country, either by natural beauty, such as the beaches or the rainforest, by the culture or the gastronomy, or the sport represented here mainly by football. When comparing both groups, it is clear that there are some similarities. They both mentioned the stereotypes of the country, such as beaches, football, and carnival. They also mentioned cities like Rio de Janeiro and São Paulo and landmarks such as Sugar Loaf and the Christ the Redeemer Statue. Besides that, they also cited other elements of Brazilian nature, cuisine, and culture. Regarding negative words, we could also find some similarities, which give us the idea that, apart from their intention, the image they have of Brazil is a mixed scenario of stereotypes, collective imaginary, and elements offered through the media coverage. Another relevant point to be highlighted in this discussion is the role of the media.

According to the analysis, respondents have created the image they have of Brazil mainly by the media content, in addition to social media and family and friends (word of mouth). The number of people who affirmed that media as the primary source of information about the country is a relevant aspect to be considered. This finding follows Lopes'20 study, which presents media as one of the primary sources of information in the perceptual and cognitive process, which the destination image is formed.

Even though a large amount of the respondents have not been reading or watching news about Brazil since the 2014 FIFA World Cup, it is necessary to highlight as well the role of media in this study, because, as the host country of the 2016 Olympic Games, Brazil will be on the scene of the international media more often and highlight other issues over, because become more recently. This might justify, for instance, some of the negative words presented in the analysis, such as "corruption" or "crimes." In the last years, news about corruption in politics has been more common in the media. Mataruna-Dos-Santos1 mentioned that problems during the Olympic Games organization period, not delete the incidents and the negative aspects that were in evidence before the 2014 FIFA Cup. 
Besides the tourism destination image, which influenced directly foreigners' intention to visit the country during the 2016 Olympic or Paralympic Games, there are other aspects related to this. According to the analysis, interest in sports can also be an essential influence for visitors. Prices, crowding, and safety and health perceptions about Brazil does not seem to be decisive aspects for the respondents.

All these findings can be related to the Preuss'14 discussion. He argues that the attractiveness of the image of the host city/country depends on extensive media coverage, available sports infrastructure, and a near-perfect event organization. Thus, the vital role of media to construct the host city or country's image in the international arena, which might influence all the aspects considered by this research, especially the image of the place as a tourism destination.

Media can be a double-edged sword that can have both positive and negative effects. The social media channels are critical to promoting a positive image to attract customers and educate the people (39-43). Since media can positively or negatively affect tourists' perceptions of a destination, mega-event organizers must develop strategies nurturing, managing, and optimizing media channels to enforce the positive influence on tourists' perceptions of a destination $(39,44$, 45).

\section{CONCLUSION}

This paper opens a relevant study of the foreigners' perceptions about Brazil as a tourist destination and how it is related to the sports mega-events that are being held in the country since 2013, with the FIFA Confederations Cup.
Much research has been made on this topic inside Brazil with tourists, however, none of them looked for a different sample: people who have never been to the country. The success in the organization of the previous mega-events cooperates to promote positive impressions for the host country. Furthermore, this research will take the next step. By analyzing a different sample, people who have already been to the country, for instance, we will be able to make comparisons and verify how the mega-events have influenced in the perceptual and cognitive process for the image of Brazil as a tourism destination to be shaped by foreigners who have different experiences with Brazil (by media, family, and friends, or their own experience after visiting the country).

\section{APPLICABLE REMARKS}

- The host city and country of mega-events depend on extensive media coverage to promote and amplify their image to attract tourists.

- The availably of sports infrastructure and a nearperfect event organization are essential targets to be included in the image promotion for host cities.

- Other aspects not related to the sports events, such as the virus epidemic, political crisis, the wave of violence, strikes, natural disasters, can affect the tourism destination image, which is influenced directly by foreigners' intention to visit the country during the Olympic or Paralympic Games.

- Mega-events promotes changes in the perceptual and cognitive process regarding the image of the nations as a tourism destination.

\section{REFRENCES}

1. Will Brazil be able to overcome domestic turmoil ahead of the Olympic Games? 2019 [cited 2020]. Available from: https://bit.ly/2IfLVev.

2. Horne J. The Four 'Cs' of Sports Mega-Events: Capitalism, Connections, Citizenship and Contradictions. Olympic Gam Mega Event Civil Soc. Hampshire: Palgrave Macmillan; 2012. p. 31-45.

3. Goig R. Repercusiones y Efectos Sociales de los Megaeventos Deportivos. Barcelona: Perspectivas científicas y estudios de caso; 2012.

4. Horne J, Manzenreiter W. An Introduction to the Sociology of Sports Mega-Events. Soc Rev. 2017;54(2_suppl):1-24. doi: 10.1111/j.1467-954X.2006.00650.x

5. Maennig W, Zimbalist A. International Handbook on the Economics of Mega Sporting Events: Edward Elgar; 2012.

6. Kasimati E. Economic aspects and the Summer Olympics: a review of related research. Int J Tourism Res. 2003;5(6):433-444. doi: 10.1002/jtr.449

7. Dos Santos M, L.J., Pena BG. Las huellas de los mega eventso: passado: UAdeO; 2018. 
8. Swart K, George R, Cassar J, Sneyd C. The 2014 FIFA World Cup ${ }^{\mathrm{TM}}$ : Tourists' satisfaction levels and likelihood of repeat visitation to Rio de Janeiro. J Destin Marke Manage 2018;8:102-113. doi: 10.1016/j.jdmm.2017.01.001

9. DaCosta LP, Miragaya AM. The Future of Sport Mega-events: Innovation and Olympic Agenda 2020. Rio de Janeiro: Engenho; 2015.

10. Getz D. Event management and event tourism. New York: Cognizant; 2005.

11.Zagnoli P, Radicchi E. Do Major Sports Events Enhance Tourism Destinations? Physic Cult Sport Stud Res 2009;47(1):44-63. doi: 10.2478/v10141-009-0031-z

12. Roche M. Megaevents and modernity: Olympics and expos in the growth of global culture. London \& New York: Routledge; 2002.

13.Please visit GlobalPeople Knowledge Exchange for up-to-date versions of these resources and more! 2019 [cited 2020]. Available from: https://bit.ly/38jlT4t.

14.Preuss H. Lasting Effects of Major Sporting Events 2006. Available from: http://goo.gl/x6v3NO.

15. George R, Swart K. International tourists' perceptions of crime-risk and their future travel intentions during the 2010 FIFA World Cup ${ }^{\mathrm{TM}}$ in South Africa. J Sport Tourism. 2012;17(3):201-223. doi: $10.1080 / 14775085.2012 .734060$

16.Leiper N, editor A town like Elis? The Olympics' impacts on tourism in Sydney. CAUTHE 1997: Tourism research: Building a better industry; Proceedings from the Australian Tourism and Hospitality Research Conference; 1997: Bureau of Tourism Research.

17.Henderson JC. Uniquely Singapore? A case study in destination branding. J Vaca Mark. 2016;13(3):261274. doi: 10.1177/1356766707077695

18. Bigné JE, Sánchez MI, Sánchez J. Tourism image, evaluation variables and after purchase behaviour: inter-relationship. Tourism Manage. 2001;22(6):607-616. doi: 10.1016/s0261-5177(01)00035-8

19. San Martín H, Rodríguez del Bosque IA. Exploring the cognitive-affective nature of destination image and the role of psychological factors in its formation. Tourism Manage. 2008;29(2):263-277. doi: 10.1016/j.tourman.2007.03.012

20.Lopes SDF. Destination image: Origins, Developments and Implications. PASOS Revista de Turismo y Patrimonio Cultural. 2011;9(2):305-315. doi: 10.25145/j.pasos.2011.09.027

21.Stabler MJ. The image of destination regions: theoretical and empirical aspects. Mark tourism ind. 1988;1:133-161.

22. Beerli A, Martín JD. Tourists' characteristics and the perceived image of tourist destinations: a quantitative analysis - a case study of Lanzarote, Spain. Tourism Manage. 2004;25(5):623-636. doi: 10.1016/j.tourman.2003.06.004

23.Stern E, Krakover S. The Formation of a Composite Urban Image. Geograp Anal. 2010;25(2):130-146. doi: 10.1111/j.1538-4632.1993.tb00285.x

24. Mazursky D, Jacoby J. Exploring the development of store images. J retail. 1986;62(2):145-165.

25. Burgess J. Image and identity (Occasional Papers in Geography, 23). UK: University of Hull Publication; 1978.

26. Tasci ADA. Assessment of factors influencing destination image using a multiple regression model. Tourism Rev. 2007;62(2):23-30. doi: 10.1108/16605370780000311

27. Yang J, Hu P, Yuan B. The impact of familiarity of perceptive behavior of tourism image-A case study of Chongqing residents' perception of Shanghai tourism image. Tourism Tribune. 2009;24(4):56-60.

28. Castro CB, Martín Armario E, Martín Ruiz D. The influence of market heterogeneity on the relationship between a destination's image and tourists' future behaviour. Tourism Manage. 2007;28(1):175-187. doi: 10.1016/j.tourman.2005.11.013

29. Court B, Lupton RA. Customer Portfolio Development: Modeling Destination Adopters, Inactives, and Rejecters. J Travel Res. 2016;36(1):35-43. doi: 10.1177/004728759703600106

30. Características do público geral e da demanda turística internacional 2013 [cited 2020]. Available from: http://goo.gl/Cb4Upp.

31.Estudo da Demanda Turística Internacional durante a Copa do Mundo da FIFA de 20142014 [cited 2020]. Available from: https://bit.ly/39oeD8W. 
32.George R, Swart K, Jenkins DW. Harnessing the power of football: safety-risk perceptions of sport tourists at the 2013 FIFA Confederations CupTM in Brazil. J Sport Tourism. 2014;18(4):241-263. doi: 10.1080/14775085.2014.944203

33. Baker DA, Crompton JL. Quality, satisfaction and behavioral intentions. Ann Tourism Res. 2000;27(3):785-804. doi: 10.1016/s0160-7383(99)00108-5

34.Boo S, Gu H. Risk Perception of Mega-events. J Sport Tourism. 2010;15(2):139-161. doi: 10.1080/14775085.2010.498257

35.Fodness D, Murray B. A Model of Tourist Information Search Behavior. J Travel Res 2016;37(3):220230. doi: $10.1177 / 004728759903700302$

36. Fakeye PC, Crompton JL. Importance of socialization to repeat visitation. Ann Tourism Res 1992;19(2):364-367. doi: 10.1016/0160-7383(92)90091-3

37. Ministério do Turismo destaca ações para as Olimpíadas em 20162015 [cited 2020]. Available from: http://goo.gl/ppMA9A.

38.Lepp A, Gibson H. Tourist roles, perceived risk and international tourism. Ann Tourism Res 2003;30(3):606-624. doi: 10.1016/s0160-7383(03)00024-0

39. Muhoho-Minni P, Lubbe BA. The role of the media in constructing a destination image: the Kenya experience. Communicatio. 2017;43(1):58-79. doi: 10.1080/02500167.2016.1226915

40. Milla A, Mataruna L, Ristic MR. Adopting Social Media for Nonprofits as a Main Marketing Tool: Analysis of a Youth Non-Profit Organization. Int J Appl Bus Econ Res. 2018;22(2).

41. Milla AC, Dos-Santos LJM. Social Media Preferences, Interrelations Between the Social Media Characteristics and Culture: A View of Arab Nations. Asian Soc Sci. 2019;15(6). doi: 10.5539/ass.v15n6p71

42. Milla AC, Kurt O, Mataruna-Dos-Santos LJ. User Perceptions of Technology Integration in Schools: Evidence from Turkey's Fatih Project. Int J Educ Pract. 2019;7(4):430-437. doi: 10.18488/journal.61.2019.74.430.437

43. Haiachi MdC, Ávila EBd, Cardoso VD, Canuto SCM, Kumakura RS, Oliveira AFSd, et al. Military rehabilitation programs and Paralympic Movement. J Hum Sport Exercise. 2020;15(1):45-56.

44. Mataruna-Dos-Santos LJ, Zardini-Filho CE, Cazorla Milla A. Youth Olympic Games: Using marketing tools to analyse the reality of GCC countries beyond Agenda 2020. J Hum Sport Exercise. 2019;14(2):391-411. doi: 10.14198/jhse.2019.14.Proc3.12

45. Azeem M, Mataruna L. Identifying factor measuring collective leadership at academic workplaces. Int J Educ Manage. 2019; ahead-of-print(ahead-of-print). doi: 10.1108/ijem-04-2018-0131 